\title{
Protective effect of $\beta$-Lactoglobulin against heat induced loss of antioxidant activity of resveratrol
}

Article

Accepted Version

Creative Commons: Attribution-Noncommercial-No Derivative Works 4.0

Guo, Y. and Jauregi, P. (2018) Protective effect of $\beta$ Lactoglobulin against heat induced loss of antioxidant activity of resveratrol. Food Chemistry, 266. pp. 101-109. ISSN 03088146 doi: https://doi.org/10.1016/j.foodchem.2018.05.108 Available at https://centaur.reading.ac.uk/77446/

It is advisable to refer to the publisher's version if you intend to cite from the work. See Guidance on citing.

To link to this article DOI: http://dx.doi.org/10.1016/j.foodchem.2018.05.108

Publisher: Elsevier

All outputs in CentAUR are protected by Intellectual Property Rights law, including copyright law. Copyright and IPR is retained by the creators or other copyright holders. Terms and conditions for use of this material are defined in the End User Agreement.

www.reading.ac.uk/centaur

\section{CentAUR}


Central Archive at the University of Reading

Reading's research outputs online 
1 Protective effect of $\beta$-Lactoglobulin against heat induced loss of antioxidant

2 activity of resveratrol

3 Yuchen Guo and *Paula Jauregi

4 Department of Food and Nutritional Sciences, Harry Nursten Building, University of Reading,

5 Whiteknights, Reading, RG6 6AP, United Kingdom

*Corresponding author

E-mail address: p.jauregi@reading.ac.uk

Address: Department of Food and Nutritional Sciences, Harry Nursten Building, University of Reading, Whiteknights, Reading, RG6 6AP, United Kingdom.

Telephone: $+44(0) 1183788728$

6

7 ABSTRACT

8 Resveratrol exhibits many health benefits however, low water-solubility and instability to

9 processing conditions such as heating can be some of the main challenges for its processing and

10 formulation. Here the complexation of $\beta$-lactoglobulin $(\beta-\mathrm{Lg})$ with resveratrol was investigated to

11 improve its solubility and stability. The solubility of resveratrol in water was determined as

$127 \mathrm{mg} / 100 \mathrm{ml}$. Resveratrol- $\beta$ - $\mathrm{Lg}$ nanoparticles $(181.8 \mathrm{~nm})$ were produced at $\mathrm{pH} 6$ and $75^{\circ} \mathrm{C}$ for 45

13 min. Heating resveratrol solutions at $75^{\circ} \mathrm{C}$ for $45 \mathrm{~min}$ resulted in isomerization of resveratrol and

14 reduced antioxidant activity. However, resveratrol- $\beta$-Lg nanocomplexes which had undergone the

15 same heat treatment exhibited improved antioxidant activity. Heating at pasteurisation conditions

16 led to similar results and both native $\beta$ - $\operatorname{Lg}$ and nanoparticles exhibited a protective effect against

17 heat induced chemical changes in resveratrol resulting in enhanced antioxidant activity. 
18 Fluorescence measurements revealed strong interactions of resveratrol with both, native protein

19 and nanoparticles.

20 Keywords: Resveratrol; $\beta$-lactoglobulin; nanoparticles; antioxidant activity; heating

\section{Introduction}

Nowadays, consumers are attracted to dietary supplements instead of drugs to improve health.

24 and $\Theta$ Oral administration is the most convenient and commonly applied method to develop new

25 nutraceuticals. Based on many studies, the predominant problem of nutraceuticals is poor

26 bioavailability due to their low aqueous solubility which, affects over $40 \%$ of the new chemical

27 entities produced by high throughput screening processes (Lipinski, 2002). Several reasons

28 contribute to the solubility problem: 1) high molecular weight; 2) high Log of the octanol-water

29 partition coefficient $(\log \mathrm{P})$, which is a measure of a drug's lipophilicity. In order to improve the

30 aqueous solubility, numerous researchers have developed many approaches such as particle size

31 reduction, crystal engineering, salt formation, solid dispersion and surfactant complexation

32 (Savjani, Gajjar., \& Savjani, 2012). New techniques like nanoparticles, nanotubes,

33 nanosuspensions and nanocomplexes are employed to improve the solubility of poorly soluble

34 drugs and nutraceuticals (Rabinow, 2004; Tran, Tran, \& Lee, 2013). Proteins like zein, whey

35 proteins, soy proteins and other natural polymers like cyclodextrins have been applied not only in

36 pharmaceutical but also in food applications (Duarte et al., 2015; Gorji et al., 2015; Pujara,

37 Jambhrunkar, Wong, McGuckin, \& Popat, 2017). Simple and safe carrier candidates, which meet

38 the GRAS (Generally Recognised As Safe) qualification and possibly have essential health

39 benefits, should be investigated to improve aqueous solubility and stability of bioactives. 
Resveratrol (3,5,4'-Trihydroxystilbene), is a typical non-flavonoid phenol that belongs to the

42 stilbene family and has various properties including antioxidant, anti-cancer, anti-inflammatory, 43 and antineoplastic (Bhat \& Pezzuto, 2002; Jang et al., 1997; Soleas, Diamandis, \& Goldberg, 44 1997). Resveratrol is thought to be one of the main contributors to the famous "French paradox": 45 despite the French people's high-fat intake, a low cardiovascular diseases incidence was found. It 46 has been ascribed partly to the red wine consumption (Catalgol, Batirel, Taga, \& Ozer, 2012).

47 Since then, the studies of resveratrol have been carried out broadly in the food and pharmacy field.

48 There are 72 different natural resources which contain resveratrol, especially grapes, peanuts and 49 blueberries (Burns, Yokota, Ashihara, Lean, \& Crozier, 2002; Jimenez-Garcia et al., 2012; Lyons 50 et al., 2003). Even though resveratrol is widely distributed in various plants and fruits, there are 51 some pharmacokinetic limitations which lead to its low bioavailability: The low water solubility, 52 labile properties, and rapid metabolism (Amri, Chaumeil, Sfar, \& Charrueau, 2012; Pund, Joshi, 53 \& Patravale, 2016). The low solubility of resveratrol in oral administration is due to the chemical 54 structure of resveratrol: two phenolic rings bonded together by a double styrene bond which leads 55 to two isometric forms ,cis- and trans-resveratrol (Gambini et al., 2015). It is believed that the 56 trans-isomeric form is more abundant than cis-resveratrol, while the trans-isomer is able to 57 transform into cis-isomer under light exposure and heating. Light exposure allows a rapid 58 isomerization of trans-resveratrol, especially in the ultraviolet radiation at $366 \mathrm{~nm}$ or at low 59 concentration (Flieger, Tatarczak-Michalewska, \& Blicharska, 2017; Gambini et al., 2015). 60 Heating not only leads to increased solubility but also results in degradation, isomerization and 61 reduction of antioxidant activity. The effect of heating on resveratrol can be complex depending 62 on temperature (Flieger et al., 2017; Lee et al., 2014). In order to overcome its low solubility and 63 low stability, encapsulation might be a solution. The encapsulation of resveratrol with a number 
64 of biopolymers has been investigated including chitosan and $\gamma$-poly (Jeon, Lee, \& Lee, 2016), soy

65 protein isolate (Pujara et al., 2017), milk protein (Gorji et al., 2015), zein (Penalva et al., 2015)

66 and $\beta$-lactoglobulin (Zhang, Liu, Subirade, Zhou, \& Liang, 2014). The main whey protein, $\beta$ -

67 lactoglobulin, plays an interesting role in transporting retinol molecules and binds small

68 hydrophobic molecules. Resveratrol has been found to bind to the surface of the hydrophobic

69 pocket of $\beta$-lactoglobulin (Liang \& Subirade, 2010; Liang, Tajmir-Riahi, \& Subirade, 2008). Thus,

$70 \beta$-lactoglobulin can be an attractive candidate as a carrier to offer a solution to both, poor solubility

71 and low stability to processing /storage conditions such as heating and light exposure.

72 In previous work of our group, $\beta$-lactoglobulin nanoparticles were found to complex with 73 caffeine (Guo, Harris, Kaur, Pastrana, \& Jauregi, 2017). Higher binding affinity of

$74 \beta$-lactoglobulin in nanoparticles form rather than in the native form was found. The aim of the 75 present work was to apply this method to produce resveratrol- $\beta$-lactoglobulin nanoparticles and 76 investigate the effect of these nanoparticles and native $\beta$-lactoglobulin on the solubility and 77 stability of resveratrol under different thermal processing conditions. The main hypothesis tested 78 here was that complexation of protein (native and/or nanoparticles) with resveratrol in aqueous 79 solution can improve its solubility and/or stability. The stability was measured in terms of 80 antioxidant activity. In addition, fluorescence measurements were carried out to gain an insight 81 into the interactions between these two molecules. 


\subsection{Material}

89 Trans-resveratrol (98\% w/w) was supplied by Evolva RES140332. The $\beta$-Lactoglobulin from

90 bovine milk $\geqslant 85.0 \%$ (PAGE), lyophilized powder L2506 was purchased from Sigma.

91 Folin-Ciocalteu reagents: Folin-Ciocalteu (F9252), and Sodium carbonate BioXtra, $\geqslant 99.0 \%$

92 (S7795) were purchased from Sigma.

93 Reagents of ABTS method: 2,2'-Azino-bis(3-ethylbenzothiazoline-6-sulfonic acid) diammonium

94 salt (ABTS) $\geqslant 98.0 \%$ (HPLC) (A1888), Potassium persulfate (K2S2O8) ACS reagent, $\geqslant 99.0 \%$

95 (21622, (土)-6-Hydroxy-2,5,7,8-tetramethylchromane-2-carboxylic acid (Trolox), 97\% (238813),

96 and ethanol, $\geqslant 99.8 \%$ (GC) (32221) were purchased from Sigma-Aldrich

97 Reagents of the ferric reducing antioxidant power (FRAP) method reagents:

98 TPTZ (2,4,6-Tris(2-pyridyl)-s-triazine) (T1253); Ferric Chloride Hexahydrate(207926) were 99 purchased from Sigma-Aldrich.

100

2.2 Determination of resveratrol solubility in water solution

102 A series of resveratrol solutions/suspensions were prepared from 1mg/100ml, 3mg/100ml,

$1035 \mathrm{mg} / 100 \mathrm{ml}, 7 \mathrm{mg} / 100 \mathrm{ml}, 8 \mathrm{mg} / 100 \mathrm{ml}$, and $9 \mathrm{ml} / 100 \mathrm{ml}$ to determine the solubility of resveratrol.

104 All the solutions/suspensions were covered by tissue paper and were stirring with a magnetic stirrer 105 at room temperature for 2 hours before any measurements. Two methods were applied to determine 106 resveratrol solubility in water solution: the direct spectrophotometric method and total phenolic 107 content by Folin-Ciocalteu method.

108 The direct spectrophotometric method: The $\lambda_{\max }$ value of resveratrol aqueous solution $109(2 \mathrm{mg} / 100 \mathrm{ml})$ was determined by using a Lambda 20 spectrophotometer (Perkin-Elmer®) and 
110 scanning UV absorption from wavelength $190 \mathrm{~nm}$ to $600 \mathrm{~nm}$ with $1 \mathrm{~nm}$ spectral bandwidth. The

111 absorbance of resveratrol solutions/suspensions was measured at the maximum wavelength by the

112 Spectrophotometers (Ultrospec ® 1100 pro) using a quartz cuvette with a path length of $1 \mathrm{~cm}$ and

113 deionized water was used as the blank. The solubility of resveratrol at room temperature was

114 determined from the plot of the absorbance against concentration as the concentration after which

115 no further significant increases were observed.

116 Folin-Ciocalteu method: The total phenolic content of all concentrations of resveratrol

117 solutions/suspensions were measured by Folin- Ciocalteu method at 760nm. In brief, $0.2 \mathrm{ml}$ of

118 resveratrol solution was added to around $6.0 \mathrm{ml}$ of deionized water into a $10 \mathrm{ml}$ volumetric flask.

119 Folin-Ciocalteu reagent $(0.5 \mathrm{ml})$ was added and mixed. After 1 minute and no longer than 8

120 minutes, $1.5 \mathrm{ml} 20 \%$ sodium carbonate solution was added and the volume adjusted to $10 \mathrm{ml}$. After

1212 hours incubation in the dark, the absorbance was recorded at $760 \mathrm{~nm}$ using a UV-Vis

122 Spectrophotometer (Ultrospec $® 1100$ pro). Deionised water was used as the blank. All the

123 experiments were carried out in triplicates, and the results were expressed in gallic acid equivalents

124 (GAE; mg/L) using a gallic acid (10-120mg/L) standard curve. The solubility of resveratrol was

125 determined as the concentration at which the GAE value reached a peak and remained constant 126 afterwards.

$127 \quad 2.3$ Production of resveratrol- $\beta$-lactoglobulin nanoparticles

128 Native $\beta$-lactoglobulin powder $(0.01 \mathrm{~g})$ was added into $5 \mathrm{ml}$ resveratrol standard solutions 129 /suspensions of varying concentrations in a $7 \mathrm{ml}$ Sterile container. Then the $\mathrm{pH}$ of the sample was 130 adjusted to 6.0 using a pH meter (Mettler Toledo, Switzerland) with $0.1 \mathrm{M} \mathrm{HCl}$ and $0.1 \mathrm{M} \mathrm{NaOH}$. 131 After this, the sample was introduced into a water bath (Grant Instrument Ltd., Cambridge, United 132 Kingdom) that have been previously heated at $75^{\circ} \mathrm{C}$. The sample was kept for 45 minutes at this 
133 temperature; it must be noted that the temperature of the sample reached the set temperature after

134 about 13 minutes. On completion of the incubation time, samples were transferred to an ice bath

135 for 10 minutes to terminate incubation. After 10 minutes in the ice bath, the $\mathrm{pH}$ of the sample was

136 measured. The particle size was determined by dynamic light scattering (DLS).

$137 \quad 2.4$ The effect of heating and native $\beta$-lactoglobulin and $\beta$-lactoglobulin nanoparticle on

138 the stability of resveratrol

139 After determination of solubility of resveratrol, all the following studies were carried out in a

140 range of concentrations of resveratrol at the solubility or below. A set of resveratrol aqueous

141 solutions in the range of solubility were used as a control and compared against samples of the

142 same concentration of resveratrol that underwent different treatments. There were three different

143 treatments: heating (see details below), the addition of native $\beta$-lactoglobulin (details below) and

$144 \quad \beta$-lactoglobulin nanoparticles (see section 2.3).

145 When studying the effect of heating, each of the resveratrol solutions/suspensions were heated 146 at $75^{\circ} \mathrm{C}$ in a water-bath for 45 minutes and moved to an ice bath for 10 minutes afterwards. Then, 147 samples were taken for analysis. This temperature was chosen as this was the temperature at which 148 the nanoparticles were formed.

150 When exploring the effect of adding native $\beta$-lactoglobulin, $0.01 \mathrm{~g}$ native $\beta$-lactoglobulin powder 151 was added to $5 \mathrm{ml}$ resveratrol standard solutions/suspensions of varying concentrations in a $7 \mathrm{ml}$ 152 Sterile container. Then samples were subjected to heat treatment.

153 The effect of heating, adding native $\beta$-lactoglobulin and $\beta$-lactoglobulin nanoparticles on the 154 stability of resveratrol were determined by total phenolic content and the total antioxidant activity. 155 For the total phenolic content, the Folin-Ciocalteu method mentioned above was applied, and when 
measuring the samples with native $\beta$-Lactoglobulin and $\beta$-Lactoglobulin nanoparticles, the

157 interference of protein was eliminated by substracting the GAE value of protein from the GAE

158 value of samples. All the samples were prepared and determined in duplicate.

159 For the total antioxidant activity, the [2,2'-Azinobis(3-Ethylbenzothiazoline-6-Sulphonic Acid)]

160 (ABTS) Free Radical Scavenging Activity Assay and Ferric ion Reducing Antioxidant Power

161 assay (FRAP) were used which are described in detail below.

162 ABTS method: The total antioxidant activity of all samples was measured by ABTS assay at

$163734 \mathrm{~nm}$, which was modified from Re et al. (1999). In general, the ABTS $^{\circ+}$ stock solution was

164 prepared by mixing solution $5 \mathrm{ml}$ ABTS solution $(7 \mathrm{mM}, 50 \mathrm{ml}$ volume, stored in an amber flask

165 and kept under refrigeration at $0-4^{\circ} \mathrm{C}$ up to one month) and $88 \mu$ l Potassium Persulfate $\left(\mathrm{K}_{2} \mathrm{~S}_{2} \mathrm{O}_{8}\right)$

166 solution $(140 \mathrm{mM}, 10 \mathrm{ml}$ volume, stored in an amber flask and dark place at room temperature up

167 to one month) together. Then the mixture was kept in the dark and room temperature for at least

$16816 \mathrm{~h}$ prior to use. For the study of phenolic compounds, the working solution of the $\mathrm{ABTS}^{\circ+}$ was

169 obtained by diluting the $\mathrm{ABTS}^{\bullet+}$ stock solution with phosphate buffered saline (PBS pH 7.4) to an

170 absorbance of $0.70 \pm 0.02$ at $734 \mathrm{~nm} .20 \mu \mathrm{l}$ of samples was added into $2 \mathrm{ml} \mathrm{ABTS}^{\bullet+}$ working solution,

171 and the mixture was homogenised by 1 mins vortex. The mixture was then incubated in the dark

172 for 6 minutes, and the absorbance $\left(\mathrm{ABS}_{\text {sample }}\right)$ was recorded at $734 \mathrm{~nm}$ using a UV-Vis

173 Spectrophotometers (Ultrospec ${ }^{\circledR} 1100$ pro). The absorbance of ABTS $^{\bullet+}$ working solution was

174 measured at the same wavelength and used as control ( $\left.\mathrm{ABS}_{\text {control }}\right)$. The PBS was to blank the

175 spectrophotometer. The percentage of scavenging activity of each sample on $\mathrm{ABTS}^{\cdot+}$ was

176 calculated as the inhibition\% (I\%) using the following equation (Shah \& Modi, 2015): Eq.(1)

$177 \quad \mathbf{I} \%=\frac{\left(\mathbf{A B S}_{\text {control }}-\mathbf{A B S}_{\text {sample }}\right)}{\mathbf{A B S}_{\text {control }}} \times \mathbf{1 0}$ 
178 When measuring the samples with native $\beta$-Lactoglobulin and $\beta$-Lactoglobulin nanoparticles,

179 the interference of protein was eliminated by subtracting the I\% of protein from the I\% of samples.

180 All the samples were prepared and determined in duplicate.

181 FRAP method: The total antioxidant activity of all samples was also assessed by FRAP method 182 at 595nm, which was modified from Benzie and Strain (1996). In principle, The stock solution of

183 FRAP method included: $300 \mathrm{mM}$ Acetate buffer $(\mathrm{pH} 3.6,2.699 \mathrm{~g}$ sodium acetate trihydrate and

$18416 \mathrm{ml}(16.8 \mathrm{~g})$ glacial acetic acid dissolved in 1L deionised water), 2,4,6-tripyridyl-s-triazine 185 (TPTZ) (10mM) in $10 \mathrm{ml} \mathrm{HCl} \mathrm{(40mM),} \mathrm{and} \mathrm{20mM} \mathrm{Ferric} \mathrm{Chloride} \mathrm{Hexahydrate} \mathrm{aqueous} \mathrm{solution.}$

186 The FRAP reagent was mixed with the $25 \mathrm{ml}$ Acetate buffer, $2.5 \mathrm{ml}$ TPTZ and $2.5 \mathrm{ml}$ Ferric chloride

187 solutions. Then, $10 \mu \mathrm{l}$ of the sample/standard was added into $300 \mu 1$ FRAP reagent in a 188 microcentrifuge tube and vortexed for 10 seconds. Then $100 \mu 1$ of this mixture, in triplicates, was 189 transferred into the microwell plate (96well, NUNC, FB) and absorbance was measured at 595nm

190 by a computer controlled Tecan Microplate reader. Results were express as the ascorbic acid 191 equivalents (AAE) using an ascorbic acid $(0.001761 \mathrm{mg} / \mathrm{ml}-0.1761 \mathrm{mg} / \mathrm{ml})$ standard curve.

192 Increased absorbance of the reaction mixture indicated greater reduction capability. When 193 measuring the samples with native $\beta$-Lactoglobulin and $\beta$-Lactoglobulin nanoparticles, the 194 interference of protein was eliminated by subtracting the AAE value of protein from the AAE 195 value of samples. All the samples were prepared and determined in triplicate.

2.5 The effect of native $\beta$-lactoglobulin and $\beta$-lactoglobulin nanoparticle on resveratrol under pasteurisation conditions

199 Different concentrations of resveratrol standard solutions/suspensions, resveratrol-native $\beta$ 200 lactoglobulin solutions and resveratrol- $\beta$-lactoglobulin nanoparticles solutions prepared using the 
201 methods above were incubated at pasteurisation conditions, $63^{\circ} \mathrm{C}$ for 30 minutes. Then the total

202 phenolic content was determined by Folin-Ciocalteu method. The total antioxidant capacity of

203 samples was measured by the ABTS method. All the samples were determined in duplicate.

$204 \quad 2.6$ Fluorescence measurement of resveratrol- $\beta$-lactoglobulin solutions

205 The concentrations of resveratrol solutions were $0.23 \mathrm{mg} / 100 \mathrm{ml}, 0.46 \mathrm{mg} / 100 \mathrm{ml}, 0.92 \mathrm{mg} / 100 \mathrm{ml}$,

$2061.84 \mathrm{mg} / 100 \mathrm{ml}$, and $2.48 \mathrm{mg} / 100 \mathrm{ml}$. The protein concentration of resveratrol-native $\beta$-Lg solutions

207 and resveratrol- $\beta$-Lg nanoparticles solutions was kept constant at $0.2 \% \mathrm{w} / \mathrm{v}$. According to Liang,

208 L., \& Subirade, M. (2012), the protein intrinsic fluorescence due to tryptophan (Trp) and tyrosine

209 (Tyr) residues is sensitive to the fluorophore environment and thus potentially an indicator of

210 changes in protein conformation. Trp in the protein emits fluorescence when excited at a

211 wavelength ( $\lambda$ ex) of $295 \mathrm{~nm}$. The protein conformational changes as a result of interactions with

212 the quencher can be studied by the changes of the intensity of emission. Therefore, the degree of

$213 \beta$-Lg conformational changes was determined based on fluorescence emission of tryptophan (Trp),

214 which was measured by fluorescence spectrophotometer with the temperature controller (Varian

215 Cary Eclipse, United Kingdom). Fluorescence spectra were obtained after excitation at 295nm,

216 scanning an emission wavelength range between $300 \mathrm{~nm}$ to $510 \mathrm{~nm}$, using $5 \mathrm{~nm}$ excitation and

217 emission slits wavelength. The data was collected by Cary Eclipse software version 2 (Varian Cary

218 Eclipse, United Kingdom) and samples were analysed at a constant temperature of $20^{\circ} \mathrm{C}$.

219 According to Liang and Subirade (2012), the fractional residual fluorescence or relative

220 fluorescence intensity $\left(\mathbf{R F I}=\mathbf{F}_{\max } / \mathbf{F}_{\mathbf{0}} \times \mathbf{1 0 0}\right)$ was the fraction of the total protein fluorescence that

221 was not quenched, and thus the fraction of $\beta$ - $\mathrm{Lg}$ not bound to the ligand; where, $\mathbf{F}_{\mathbf{0}}$ is fluorescence

222 intensity of pure $\beta-\mathrm{Lg} ; \mathbf{F}_{\max }$ is the intensity at the emission maximum $\left(\boldsymbol{\lambda}_{\max }\right)$. A low ratio of RIF

223 demonstrated a strong binding of the ligand, while a ratio of $100 \%$ indicated no binding. 
224 For the calculation of binding constant and binding number, the fluorescence quenching data 225 were analysed by fitting to the Stern-Volmer equation (Liang et al., 2008) in dynamic quenching.

226 Eq. (2):

$227 \quad \mathbf{F}_{\mathbf{0}} / \mathbf{F}_{\max }=\mathbf{1}+\mathbf{K}_{\mathbf{q}} \times \tau_{\mathbf{0}} \times[$ Resveratrol $]=\mathbf{1}+\mathbf{K} \times[$ resveratrol $]$

$228 \mathbf{F}_{\mathbf{0}}$ and $\mathbf{F}_{\max }$ are the fluorescence emission intensities without and with resveratrol; [resveratrol]

229 is resveratrol concentration; $\mathbf{K}_{\mathbf{q}}\left(\mathrm{M}^{-1} \mathrm{~s}^{-1}\right)$ is the fluorescence quenching rate constant; $\tau_{\mathbf{0}}(\mathrm{s})$ is the

230 fluorophore fluorescence lifetime without quencher, and $\mathbf{K}\left(\mathbf{K}_{\mathbf{q}} \times \mathbf{\tau} \mathbf{0}\right)$ is defined as the Stern-

231 Volmer quenching constant. By plotting Fo/Fmax as a function of [resveratrol] and according to

232 Eq. (2) $\mathbf{K}$ was obtained from the slope of the straight line.

233 For the static quenching, the binding constant $\mathbf{K}_{\mathbf{s}}$ and binding number $\mathbf{n}$ can be calculated 234 according to the double logarithmic equation (He et al., 2016) Eq. (3):

$\left.235 \log \left[\left(\mathbf{F}_{\mathbf{0}}-\mathbf{F}_{\max }\right) / \mathbf{F}_{\max }\right)\right]=\log K_{S}+\mathbf{n} \log [$ resveratrol $]$

237 From a plot of $\log \left(\mathrm{F}_{\mathrm{o}}-\mathrm{Fmax} / \mathrm{F}_{\mathrm{o}}\right)$ as a function of $\log$ [resveratrol] and according to Eq. 3 the Ks 238 value was obtained from the intercept of the resulting straight line and $\mathrm{n}$ from the slope.

\subsection{The stability of resveratrol to light}

Resveratrol solutions/suspensions were exposed to overhead light (Philips, TL-D 840, 70w, and

242 distant was 1 meter) in the laboratory during $0,1,3,6$ and 12 hours. The total phenolic content 243 was measured at $303 \mathrm{~nm}$ by a spectrophotometer (Ultrospec ${ }^{\circledR} 1100$ pro) and the Folin-Ciocalteu 244 method as described above. The total antioxidant capacity of samples was measured by ABTS as 245 described above. All the samples were determined in duplicate.

\section{$246 \quad$ 2.8. Statistical analysis}


248 USA). The results were statistically analysed by analysis of variance using IBM® SPSS®

249 Statistics version 20.0. Means and standard deviations from at least two measurements carried out

250 on two samples repeated. The significance level was set at 0.05. Data fitting of experimental data

251 to models was performed with Excel MS Office 2013 (Microsoft Corporation, Redmond, WA,

252 USA)

\section{3. Results and discussion}

\section{$254 \quad 3.1$. The solubility of resveratrol in aqueous solutions}

255 The solubility of resveratrol in water was determined by measuring total phenolic content using

256 the direct spectrophotometric method and Folin-Ciocalteu method (Fig S1).

257 In the direct spectrophotometric method, the $\lambda_{\max }$ of $2 \mathrm{mg} / 100 \mathrm{ml}$ resveratrol aqueous solution was

258 determined as $303 \mathrm{~nm}$. Therefore, solubility was measured by measuring absorbance of a range of

259 concentrations at this wavelength. The absorbance of resveratrol reached a peak and levelled off

260 at resveratrol concentration $7 \mathrm{mg} / 100 \mathrm{ml}$ after an approximately linear increase. Results from Folin-

261 Ciocalteu method showed the same trend, and at 7mg/100ml the GAE also remained constant at

262 about $35.5 \mathrm{mg} / \mathrm{L}$. Both these results indicated that $7 \mathrm{mg} / 100 \mathrm{ml}$ corresponded to the limit of

263 solubility of resveratrol in water. Surprisingly, it was in disagreement with the reported solubility

264 value $(3 \mathrm{mg} / 100 \mathrm{ml})$, but this was determined by high-performance liquid chromatography (HPLC)

265 (Jeon et al., 2016; Pujara et al., 2017). Moreover, the solubility value reported by Camont et al.

266 (2009) using the UV spectrophotometric method was $6.85 \mathrm{mg} / 100 \mathrm{ml}$, but they claimed that this

267 increased solubility was due to sonication which helped to dissolve resveratrol. Another possible

268 explanation of this different result was that, in our method, samples were not filtered prior to

269 absorbance measurements, so any insoluble particles of resveratrol in suspension could have led 
270 to an overestimation of the solubility. However, in the Folin assay, $0.5 \mathrm{ml}$ samples were taken and

27120 times dilution was applied so any interferences by suspended particles would be minimal. In

272 any case filtration was not an option in this study as filtration of aqueous solutions of resveratrol

273 with a $0.45 \mu \mathrm{m}$ Polyethersulfone (PES) membrane proved to be very difficult and all resveratrol

274 was retained (results obtained by HPLC but not shown here). Only the $0.22 \mu \mathrm{m}$ Polypropylene

275 (PVDF) filters showed high permeability for resveratrol but still, a reduction in absorbance

276 (7.69\%) was observed. Moreover, with this filter high retention of $\beta$ - $\operatorname{Lg}$ nanoparticles (about $80 \%$ )

277 was obtained and that also resulted in retention of resveratrol. Therefore, as filtration is a key step

278 before injecting the samples into the column, HPLC was not used in this study to determine the

279 concentration of resveratrol.

280 To sum up, in this study, the solubility of resveratrol in deionized water at room temperature 281 was $7 \mathrm{mg} / 100 \mathrm{ml}$. As our solubility result was higher than some of the reported values, it was 282 assumed that at $7 \mathrm{mg} / 100 \mathrm{ml}$, a nearly saturated solution of resveratrol was obtained. Therefore, 283 the rest of experiments were carried out at the range of $1 \mathrm{mg} / 100 \mathrm{ml}$ to $7 \mathrm{mg} / 100 \mathrm{ml}$.

\subsection{The effect of light on resveratrol solubility and stability}

286 For the stability to light, the resveratrol suspensions were exposed to the lab light for 12 hours.

287 Based on the measurement of the direct spectrophotometric method, the concentration of 288 resveratrol had an increasing trend with one exception at 1mg/100ml (Fig 1). Also, according to 289 Figure 1, there was a reduction of GAE value at $1 \mathrm{mg} / 100 \mathrm{ml}$, but no significant difference at $2903 \mathrm{mg} / 100 \mathrm{ml}-7 \mathrm{mg} / 100 \mathrm{ml}$ during 12 hours light exposure with a wide variance. Corresponding to 291 the total phenolic content, inhibition\% had the same increasing trend at $3 \mathrm{mg} / 100 \mathrm{ml}-7 \mathrm{mg} / 100 \mathrm{ml}$. 292 A significant positive correlation between total phenolic content (the direct spectrophotometric 
293 method) and total antioxidant capacity was observed as Pearson value was 0.844 . Therefore, it was

294 concluded that the resveratrol solution was not stable when exposed to lab light. Simimalrly, 295 Pinelo, Rubilar, Sineiro, and Núñez (2005) found that resveratrol solution achieved maximum 296 antioxidant activity at $22^{\circ} \mathrm{C}$ in water bath after three days.

297 Also, according to Orgován, Gonda, and Noszál (2017), the trans-resveratrol is more lipophilic 298 than its isomer. Moreover, they also found that the cis-resveratrol has over ten times more 299 solubility than trans-resveratrol. Another potential explanation could be that at high concentration, 300 the trans-resveratrol converted to cis-resveratrol under the light condition and more cis-resveratrol 301 dissolved in the solution leading to an increase in antioxidant activity.

A

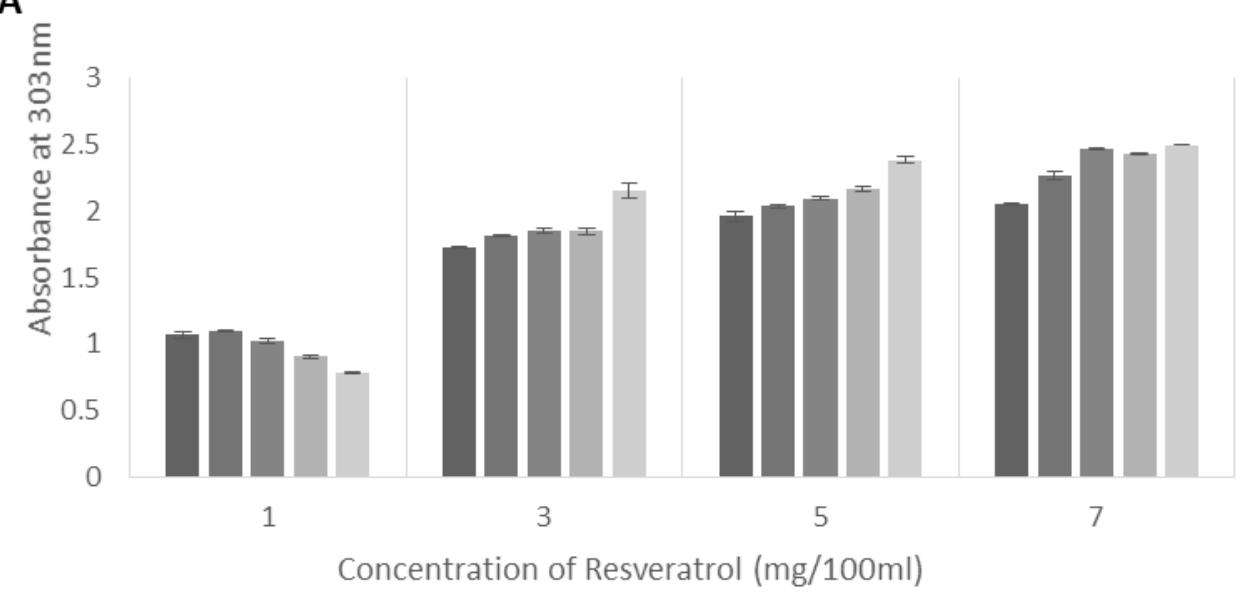

302

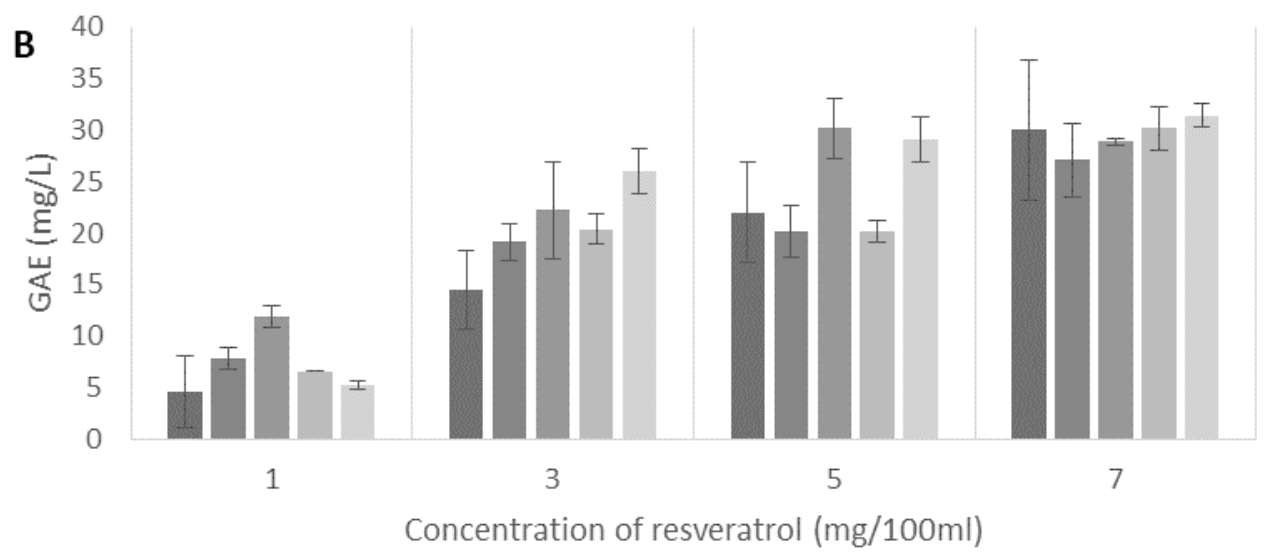




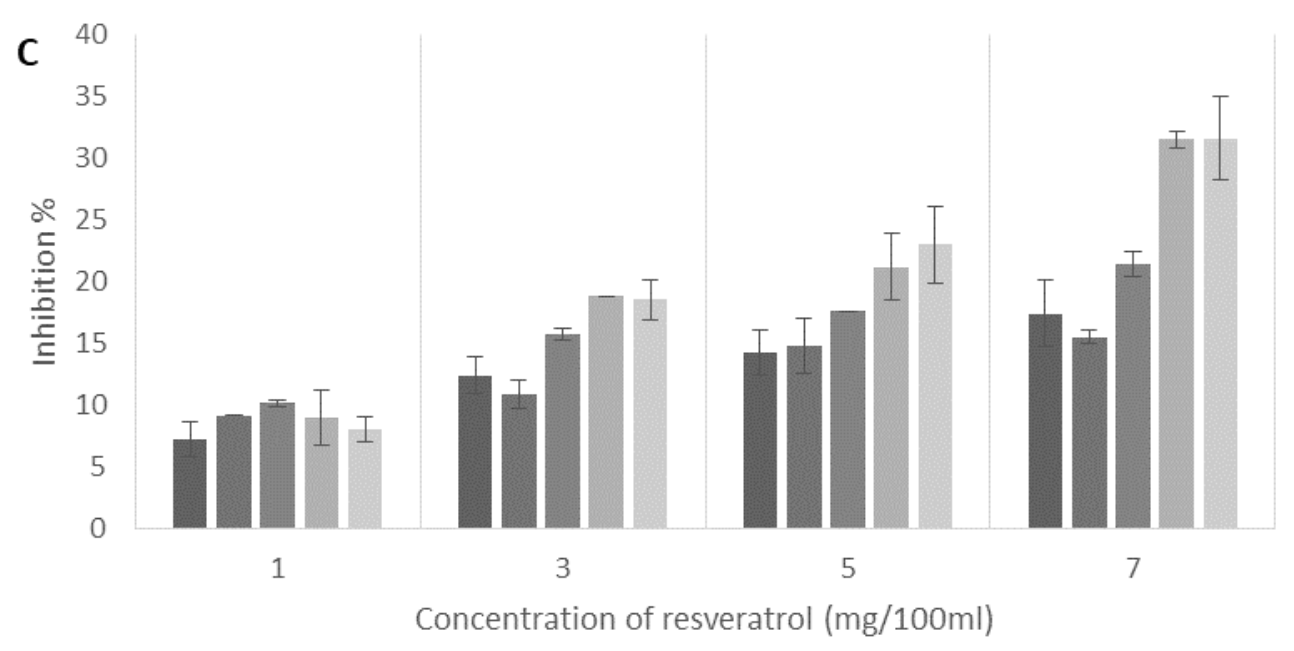

304

305 Figure 1: the stability of resveratrol to light by total phenolic content at $303 \mathrm{~nm}(\mathrm{~A})$, total phenolic 306 content by Folin-Ciocalteu method (B) and total antioxidant capacity by ABTS (C). $\square$ 0h $\square$ 1h $3073 \mathrm{~h} \square 6 \mathrm{~h} \square 12 \mathrm{~h}$.

$308 \quad 3.3$. The characterization of resveratrol- $\beta$-lactoglobulin nanoparticles

309 After heating the mixture of resveratrol and $\beta$-lactoglobulin $(0.2 \% \mathrm{w} / \mathrm{v})$ to form nanoparticles, 310 the size of nanoparticles was measured by dynamic light scattering. The average size of 311 resveratrol- $\beta$-lactoglobulin nanoparticle was $181.80 \mathrm{~nm} \pm 1.48 \mathrm{~nm}$ with polydispersion index 0.048 .

312 The nanoparticle size was close to that reported by Fonseca, Khalil, and Mainardes (2017) who 313 encapsulated resveratrol with bovine serum albumin nanoparticles $(175 \mathrm{~nm})$ by desolvation method 314 with ethanol. There was no significant difference in size among different concentrations of 315 resveratrol nanoparticles and nanoparticles alone. So the nanoparticles $(200 \mathrm{~nm})$ produced were not 316 affected by the concentrations of resveratrol. On the other hand, the size of nanoparticles was 317 smaller than the nanoparticles we produced in our previous work (Guo et al 2017) and this is 318 possibly because no hydration step (at $4{ }^{\circ} \mathrm{C}$ overnight) was applied prior to the production of 
nanoparticles. Here no hydration step was applied in order to reduce any risk of resveratrol

320 degradation during storage.

\section{on the stability of resveratrol}

324 The effect of heating was investigated under the same conditions as those used in the $\beta$ -

325 lactoglobulin nanoparticles preparation: heating at $75^{\circ} \mathrm{C}$ for 45 mins. After heating, 10 minutes in

326 the ice bath allowed rapid reduction of samples temperature to room temperature. The

327 concentration of native $\beta$-lactoglobulin added to the resveratrol solution was the same as that used

328 in the preparation of nanoparticles. The stability of resveratrol solutions was assessed after: (i)

329 heating, (ii) protein addition and (iii) nanoparticles production; this was assessed by comparing

330 the total phenolic content (Folin-Ciocalteu method), and total antioxidant activity (ABTS method

331 and the FRAP method) of treated samples with those of the control (resveratrol aqueous solution

332 1mg/100ml-7mg/100ml).

\section{3.4.1. Total phenolic content by Folin-Ciocalteu method}

334 A clear increment of GAE value was observed after heating at all concentrations (Fig 2),

335 indicating that the heating has a significant influence on resveratrol. Even though heating could

336 improve the solubility of resveratrol in water dramatically (Filipa et al., 2003) since in this study

337 all samples were subjected to an ice bath after heating, the increase of solubility due to heating

338 would have been reduced or eliminated. So the increase in GAE observed at all concentrations,

339 particularly those below the solubility $(<7 \mathrm{mg} / 100 \mathrm{ml})$ could be due to chemical changes in the

340 molecule which resulted in changes in its oxidative status and/or oxidation power and led to

341 enhanced blue colour production. However, at $7 \mathrm{mg} / 100 \mathrm{ml}$, the big increase in GAE from 30.01 
342 to $81.46 \mathrm{mg} / \mathrm{L}$ may also be partly due to an increase in solubility since near saturation might have

343 been reached at this concentration of resveratrol. Flieger et al. (2017) pointed out that when the

344 temperature reached $75^{\circ} \mathrm{C}$ or above, heating could induce the isomerization of resveratrol from

345 trans-resveratrol to cis-resveratrol even without light. Also, Orgován et al. (2017) found that the

346 solubility of cis-resveratrol was over ten times more than that of trans-resveratrol in water as trans-

347 resveratrol was more lipophilic than its isomer. Thus, a possible explanation for the increase in

348 GAE observed here could be that some of the trans-resveratrol isomerized to cis-resveratrol and

349 that led to an increase in solubility.

350 When adding native $\beta$-lactoglobulin, an increase in total phenolic content happened although

351 this increase was not significant $(\mathrm{P}>0.05)$ compared with the control sample at all concentrations.

352 The interference of protein on total phenolic content measurement has been eliminated by 353 subtracting the GAE value corresponding to the protein to the total GAE value (see Methods in

354 2.3). So it can be assumed that any increases in GAE as a result of protein addition were due to 355 interactions between native $\beta$-lactoglobulin and resveratrol.

356 Moreover, the samples of resveratrol with $\beta$-lactoglobulin nanoparticles had the largest 357 increment in phenolic content among these three treatments, and it was around three times the 358 phenolic content of the control sample at all concentrations (Fig 2). Interestingly the nanoparticles 359 (combined effect of heat and protein addition) led to a much higher increase than the heating alone

360 for those concentrations of RSV below solubility whereas for the highest concentration it had 361 almost the same effect than heating alone.

362 Overall these results suggest that at concentrations below saturation heating enhanced 363 resveratrol and $\beta$-lactoglobulin interactions as well as inducing isomerisation thus, these combined 
364 effects led to an increase in total phenol content. For the highest resveratrol concentration which 365 was about saturation point heating had the strongest effect and led to a further increase in solubility. 366

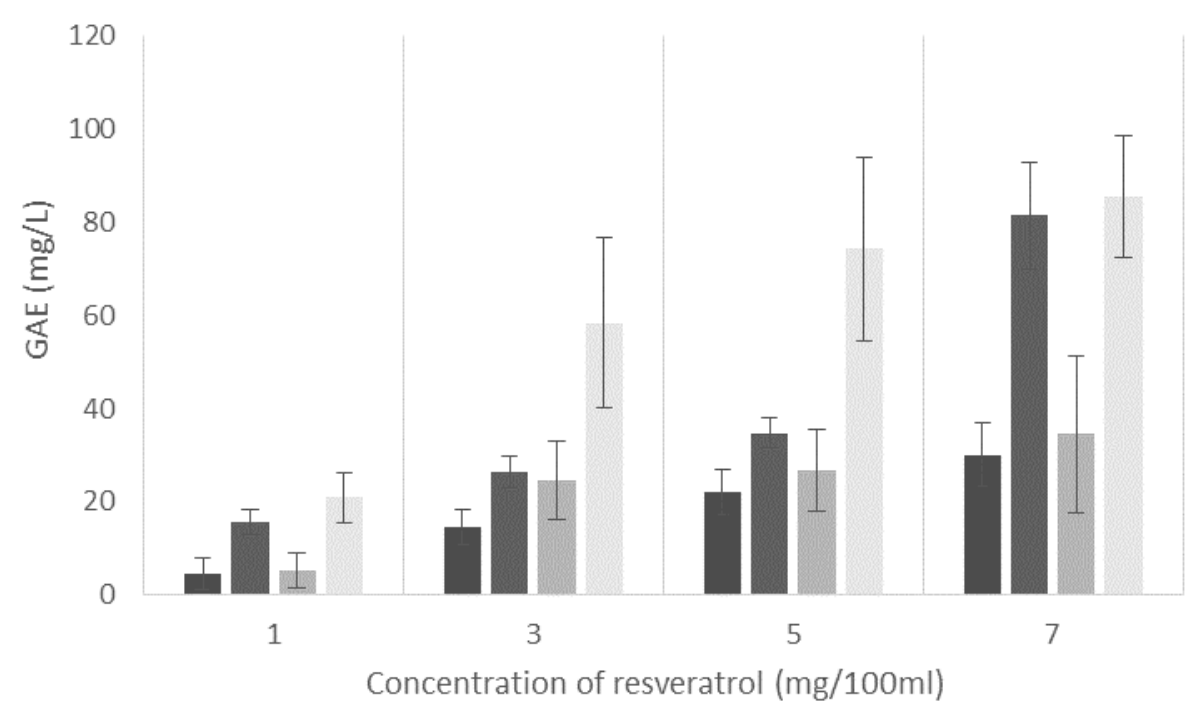

368 Figure 2: The total phenolic content results by Folin-Ciocalteu method of: $\mathbf{m}$ resveratrol aqueous 369 solution (control); $\square$ heated resveratrol; $\square$ resveratrol with native $\beta$-Lg; $\square$ resveratrol with 370 nanoparticles of $\beta$-Lg. Results were expressed as Gallic Acid Equivalents GAE mg/L.

\section{$371 \quad$ 3.4.2. Total antioxidant activity by ABTS and FRAP methods}

372 Besides total phenolic content, the total antioxidant capacity of resveratrol was measured to 373 assess changes as a result of the different treatments and in this way assess the stability of 374 resveratrol. In this work, two methods were applied to measure antioxidant capacity: ABTS 375 method and FRAP method. Results in Fig 3.demonstrated a reduction in antioxidant activity 376 (inhibition \%) after heating at all concentrations $(\mathrm{P}<0.05)$. According to Mikulski, Gorniak, and 377 Molski (2010), trans-resveratrol was a stronger antioxidant than cis-isomer due to the planar 378 conformation; this conformation would ensure the main parameters contributing to antioxidant 
379 activity: favourable spin and unpaired electron distribution. Therefore, this reduction in antioxidant

380 activity supports further the hypothesis that trans-resveratrol changed to cis-isomer during heating

381 with the subsequent reduction in antioxidant activity and increase in total phenols (as shown in Fig 382 2).

383 The addition of native $\beta$-lactoglobulin led to no significant changes in antioxidant activity when 384 compared against the control samples, indicating that the antioxidant activity would not be masked 385 by ß-lactoglobulin.

386 On the other hand, the resveratrol- $\beta$-lactoglobulin nanoparticles had higher activity than heated 387 samples $(\mathrm{P}<0.05)$ at $1-5 \mathrm{mg} / 100 \mathrm{ml}$. So the reduction in activity due to heating was counteracted 388 by the interactions of resveratrol with the nanoparticles which led to similar or higher activity than 389 the control. This suggests a protective effect of $\beta$-lactoglobulin nanoparticles against heat-induced 390 loss of antioxidant activity; possibly the interactions of $\beta$-Lg nanoparticles with resveratrol hinder 391 its isomerisation. Interestingly, at $7 \mathrm{mg} / 100 \mathrm{ml}$, the difference in antioxidant activity between the 392 heated sample (14.52\%) and resveratrol- $\beta$-lactoglobulin nanoparticle samples (21.31\%) was not 393 statistically significant ( $\mathrm{p}=0.072$ ). At $7 \mathrm{mg} / 100 \mathrm{ml}$, the heating led to two counteracting effects:

394 (1) improving solubility which would increase activity and (2) isomerization which would result 395 in reduced activity, this is why both the heating effect and the nanoparticles did not have a 396 significant impact on antioxidant activity at this concentration 397 


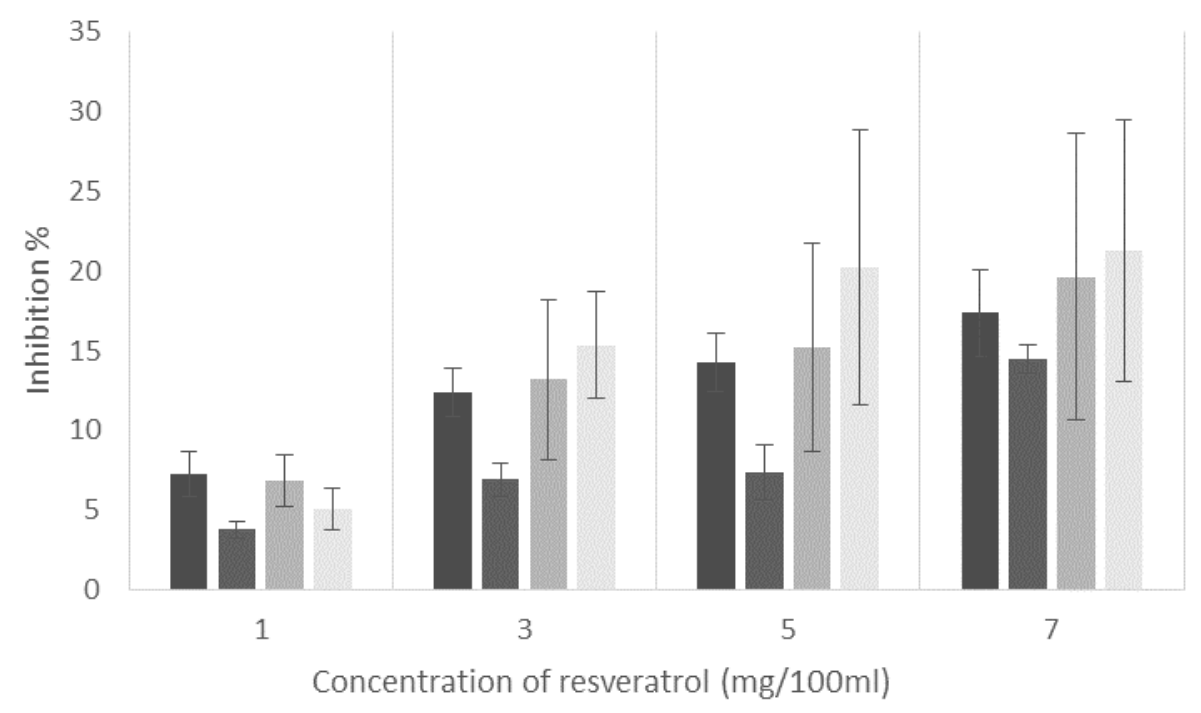

398

399 Figure 3: The total antioxidant activity results by ABTS method of: resveratrol aqueous solution 400 (control); $\square$ heated resveratrol; $\square$ resveratrol with native $\beta$ - $\mathrm{Lg} \square$ resveratrol with nanoparticles of $401 \quad \beta$-Lg. Results were expressed as inhibition\% (I\%)

402 Another antioxidant activity measuring method, FRAP, was also applied to study the effects of 403 different treatments on resveratrol. The antioxidant activity results by FRAP method expressed as 404 AAE $(\mathrm{mg} / \mathrm{ml})$ are shown in Fig 4. It was noted that there was no significant difference $(\mathrm{P}<0.05)$ in 405 activity between $5 \mathrm{mg} / 100 \mathrm{ml}$ and $7 \mathrm{mg} / 100 \mathrm{ml}$ of control samples, which might suggest that 406 solubility of resveratrol in water was $5 \mathrm{mg} / 100 \mathrm{ml}$ instead of $7 \mathrm{mg} / 100 \mathrm{ml}$.

407 A reduction in activity due to heating was observed for samples up to $5 \mathrm{mg} / 100 \mathrm{ml}$ in agreement 408 with ABTS measurements (Fig 3). Surprisingly, a sharp increase was observed at 7mg/100ml. This 409 observation agrees with the sharp increase measured in total phenolic content at this concentration 410 (Fig 2). Therefore, the increase in antioxidant activity at $7 \mathrm{mg} / 100 \mathrm{ml}$ could be explained by an 411 increase in solubilized resveratrol in the form of cis-resveratrol as a result of heating. 


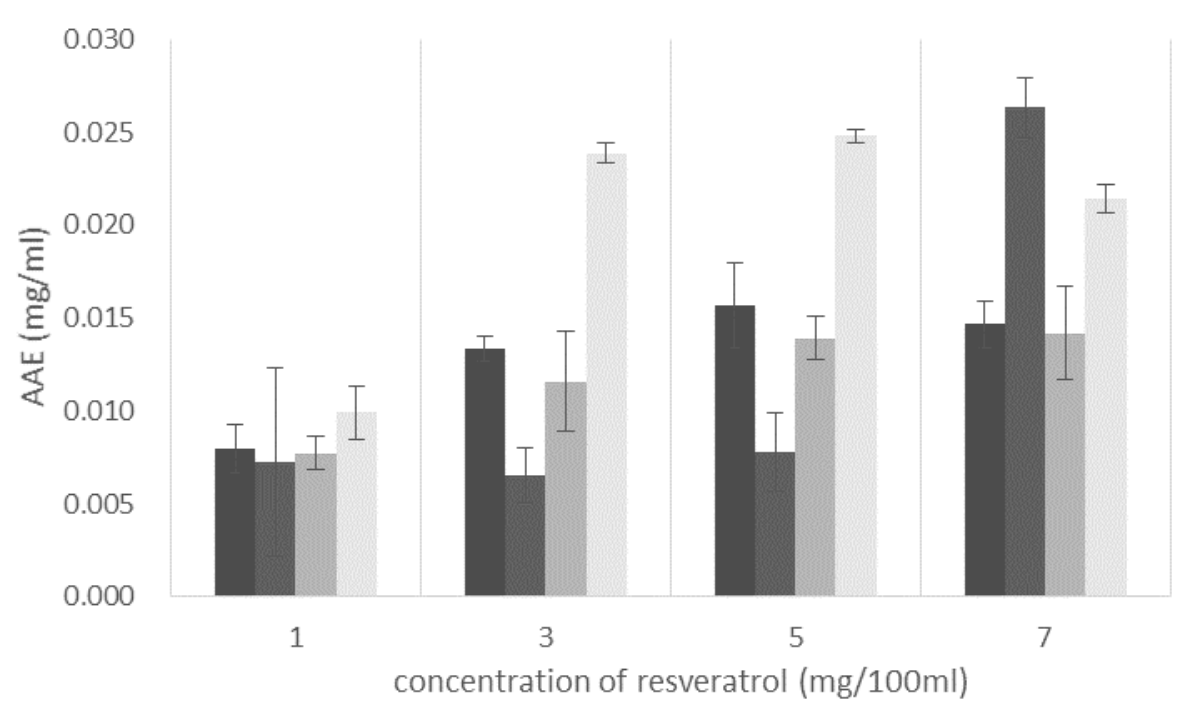

413

414 Figure 4: The total antioxidant activity results by FRAP method of: $\mathbf{m}$ resveratrol aqueous solution

415 (control); $\square$ heated resveratrol; $\square$ resveratrol with native $\beta$-Lg; $\square$ resveratrol with nanoparticles 416 of $\beta$-Lg. Results were expressed as Ascorbic Acid Equivalents (AAE mg/ml)

417 In agreement with ABTS results the resveratrol- $\beta$-lactoglobulin nanoparticles had the highest AAE 418 value at all concentrations among all treatments (except heated sample at $7 \mathrm{mg} / 100 \mathrm{ml}$ ), whilst 419 resveratrol with native $\beta$-lactoglobulin samples had the same antioxidant activity as the control 420 samples $(\mathrm{P}>0.05)$ (Fig 4). So these results again confirm a protective effect of $\beta$-lactoglobulin 421 nanoparticles against heat-induced loss of antioxidant activity. Moreover, according to the FRAP 422 method, there was a significant effect of $\beta-\operatorname{Lg}$ nanoparticles as compared to native $\beta-\operatorname{Lg}$ (Fig 4).

423 To conclude, the results of both antioxidant capacity methods indicated that $\beta$-lactoglobulin 424 nanoparticles had the ability to prevent chemical changes in resveratrol during heating and in this 425 way protect its antioxidant capacity. 


\subsection{The effect of pasteurization on stability of resveratrol with and without protein}

429 In order to study further the protective effect of $\beta$-lactoglobulin against thermal degradation of 430 resveratrol an industrial thermal process, pasteurisation, was applied to resveratrol with and

431 without protein. Pasteurisation is a common commercial method to minimise health hazards from

432 food pathogens and to extend shelf life for liquid food and drinks. Thus, it is important to examine

433 the effect of pasteurisation on resveratrol stability and how would adding protein affect this.

434 Firstly, as shown in Fig 5A, the total phenolic content of resveratrol after pasteurisation showed

435 the same results as the heating at $75^{\circ} \mathrm{C}$ : dramatic increase of GAE value after pasteurisation.

436 Secondly, it demonstrated that pasteurising resveratrol with native $\beta$-lactoglobulin had no

437 significant effect in total phenolic content at all concentrations as compared to control. However,

438 pasteurization of resveratrol with nanoparticles showed a significant decrease in total phenolic

439 content. A possible reason could be that the interaction with $\beta$-lactoglobulin suppressed the

440 isomerization undergone by resveratrol at $63^{\circ} \mathrm{C}$ This would agree with the observations above.

441 On the other hand, the antioxidant activity (\%inhibition) of standard resveratrol slightly reduced

442 after pasteurisation at $1 \mathrm{mg} / 100 \mathrm{ml}$ and $3 \mathrm{mg} / 100 \mathrm{ml}$ but increased at $5 \mathrm{mg} / 100 \mathrm{ml}$ and $7 \mathrm{mg} / 100 \mathrm{ml}$

443 (Fig 5B). These results were different to results of heating at $75^{\circ} \mathrm{C}$, which indicated that heating at

$44475{ }^{\circ} \mathrm{C}$ led to more degradation than at $63^{\circ} \mathrm{C}$, and here samples were not put in an ice bath after

445 pasteurisation so heating might have led to increased solubility.

447 Moreover by comparing the pasteursised samples with and without protein it is clear that the 448 presence of protein led to higher antioxidant activity. The increment of total antioxidant activity 449 after pasteurisation in the samples containing protein could be explained as above, ie: the 
450 interactions between resveratrol and protein hindered the isomerisation of resveratrol that led to 451 reduced activity.

452

453
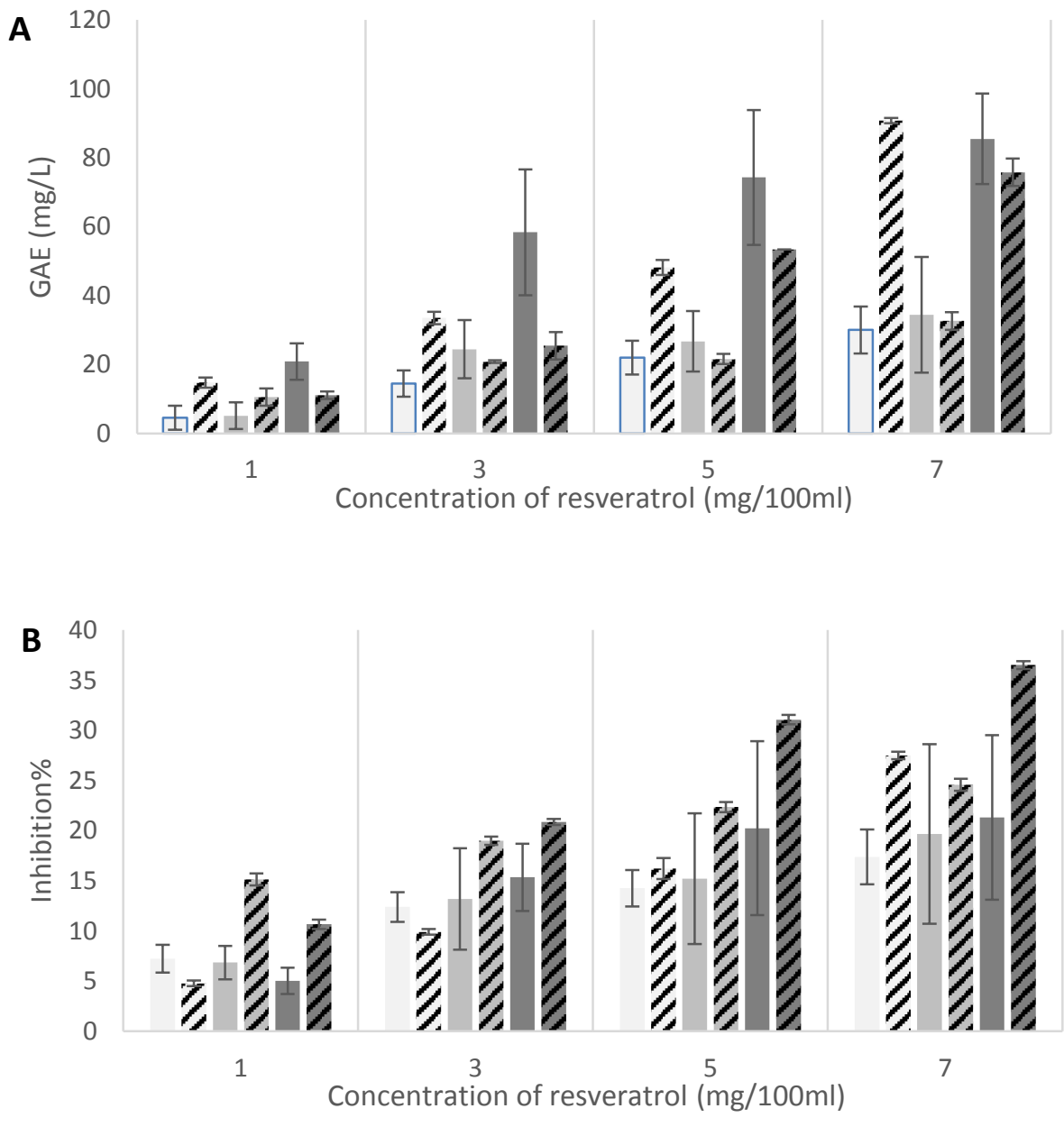

455 Figure 5: The total phenolic content (A) and the total antioxidant activity (B) of :

456 resveratrol aqueous solution (control); $\quad$ resveratrol with native $\beta$-Lg; $\square$ resveratrol with $\beta$-Lg 457 nanoparticles. The plane colour bars were samples before pasteurisation and the patterned bars the 458 same sample after pasteurisation.

460 To conclude, adding protein particularly in the nano form would suppress the heating effect on 461 resveratrol. Pasteurisation led to a small decrease in AOC at all concentrations (except at the 
462 highest) whilst resveratrol samples with protein (both in native and nanoparticle form) showed an 463 increase in AOC.

464

465 3.6. Determination of $\beta$-lactoglobulin-resveratrol interactions by fluorescence

466 Fluorescence measurements were carried out in order to obtain a further insight into the 467 resveratrol-protein interactions. The fluorescence measurements of resveratrol- $\beta$-lactoglobulin 468 solutions were conducted at constant protein concentration (for both native and nanoparticles) with 469 varying concentration of resveratrol from $0.23 \mathrm{mg} / 100 \mathrm{ml}-2.5 \mathrm{mg} / 100 \mathrm{ml}$.

470
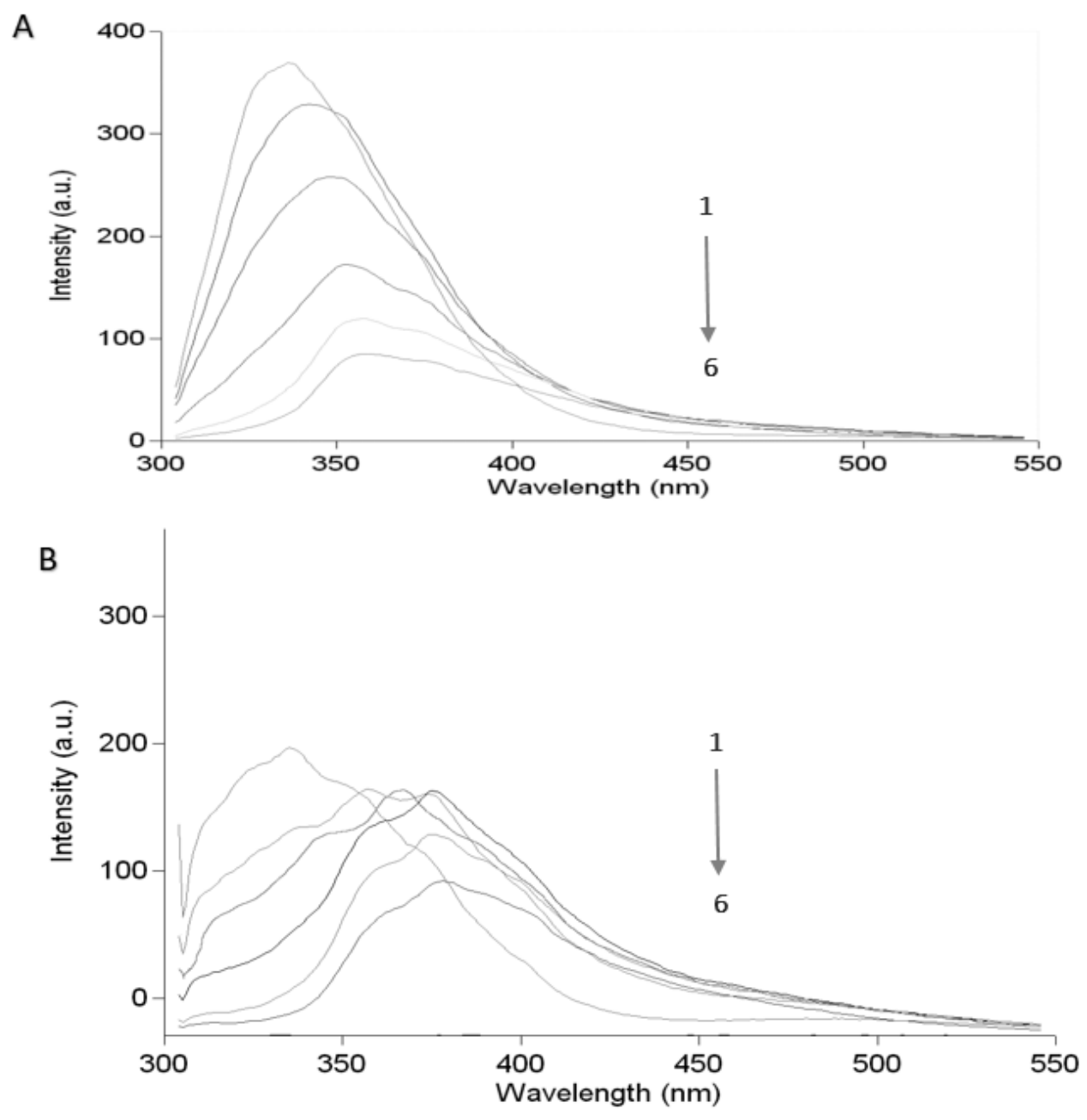
472 Figure 6: The fluorescence emission spectra of (A) resveratrol-native $\beta-\mathrm{lg}$ at $0 \mathrm{mg} / 100 \mathrm{ml}-$ $4732.48 \mathrm{mg} / 100 \mathrm{ml}$ resveratrol (1-6); (B) resveratrol- $\beta-1 \mathrm{lg}$ nanoparticle at $0 \mathrm{mg} / 100 \mathrm{ml}-2.48 \mathrm{mg} / 100 \mathrm{ml}$ 474 resveratrol (1-6).

475 Fig 6 (A) showed the intrinsic fluorescence emission spectra of native $\beta$-Lg in presence of 476 different concentrations of resveratrol. As resveratrol concentration increased, a reduction in 477 intensity of fluorescence emission was observed. This was an indication of partial disruption of 478 the protein structure which led to a change in the polarity of the fluorophore (Trp groups in the 479 protein) and hence the reduced intensity. There was also a slight shift in $\lambda_{\max }$ to longer wavelengths 480 (from $337.0 \mathrm{~nm}$ to $357.14 \mathrm{~nm}$ ) which is in agreement with the protein conformational changes 481 induced by the resveratrol as reported by Liang et al. (2008). Interestingly the changes in 482 fluorescence intensity at increased resveratrol concentrations were not as big for the $\beta$ - $\mathrm{Lg}$ 483 nanoparticles (Fig 6B) as for the native protein. The RFI value of native $\beta-\operatorname{Lg}(22.82 \%)$ was higher 484 than the RFI value of $\beta$ - Lg nanoparticles (46.65\%) indicating stronger interactions between these 485 two molecules when $\beta$-Lg is in native than in nanoparticle form. The nanoparticles were formed 486 by heat denaturation of protein; as the protein conformation had been already altered the addition 487 of resveratrol did not lead to important changes in fluorescence intensity. However, the $\lambda_{\max }$ shift 488 was much bigger for the nanoparticles than for the native protein (from $335.08 \mathrm{~nm}$ to $377.89 \mathrm{~nm}$ ) 489 suggesting a big change in the fluorophore environment towards a more hydrophilic environment.

490 This could be explained by hydrophobic interactions between the resveratrol and the unfolded 491 protein molecule which would lead to further exposure of the fluorophore to a more hydrophilic 492 media. Therefore, there was a large effect on the protein tertiary structure. Overall this seems to 493 agree with the stronger effect observed on the stability of resveratrol by the nanoparticles than the 494 native protein. 
Furthermore, from the linear plot of Fmax/Fo as a function of resveratrol concentration and

496 according to to $\mathrm{Eq}(2)$ the Stern-Volmer equation constant K of Resveratrol with native $\beta$-Lg was

$4973.18 \times 10^{4} \mathrm{M}^{-1}\left(\mathrm{R}^{2}=0.986\right)$. Assuming that $\boldsymbol{\tau}_{0}$ was $1.28 \mathrm{~ns}$ for Trp of $\beta$ - $\mathrm{Lg}$ (EricDufour, Genot, \&

498 Haertlé, 1994; Stojadinovic et al., 2013) the $\mathrm{K}_{\mathrm{q}}$ was determined as $2.5 \times 10^{13} \mathrm{M}^{-1} \mathrm{~s}^{-1}$, which was

499 higher than the maximal dynamic quenching constant $\left(1-2.0 \times 10^{10} \mathrm{M}^{-1} \mathrm{~s}^{-1}\right)$. This suggests that

500 binding of resveratrol with $\beta$-Lg followed a static quenching mechanism where the fluorophore

501 formed a stable complex with another molecule that was non-fluorescent. This result was in

502 agreement with that reported by Liang and Subirade (2012) and Liang et al. (2008), who

503 confirmed that $\beta$-Lg fluorescence quenching induced by resveratrol is a static quenching. Thus,

504 from the linear equation of $\log \left(\mathbf{F}_{\mathbf{0}}-\mathbf{F m a x}\right) / \mathbf{F m a x}$ as a function of $\log \left[\right.$ resveratrol] $\left(\mathrm{R}^{2}=0.985\right)$

505 and according to Eq. 3 the binding constant $\mathbf{K}_{\mathbf{s}}$ was determined from the intercept of the slope as

$5061.67 \times 10^{5} \mathrm{M}^{-1}$ and from the slope the binding number, $\mathrm{n}$ was obtained as 1.33 . This means 1.33

507 resveratrol molecules bind one $\beta$ - $\mathrm{Lg}$ molecule and also $\mathbf{K}_{\mathbf{s}}$ was in the range of $10^{5}$ and $10^{6} \mathrm{M}^{-1}$,

508 which was in agreement with binding constants reported for native $\beta$-Lg and a range of

509 substrates such as folic acid with $\mathbf{K}_{\mathbf{s}}=4.3 \times 10^{5} \mathrm{M}^{-1}$ (Liang \& Subirade, 2010) and EGCG with

$510 \mathbf{K}_{\mathbf{s}}=1.05 \times 10^{5} \mathrm{M}^{-1}$ (Shpigelman, Israeli, \& Livney, 2010). However, the Stern-Volmer quenching

511 equation might not be suitable to apply to the resveratrol- $\beta$ - $L g$ nanoparticles binding since the $\beta$ -

512 Lg fluorescence emission maximum changed with resveratrol concentration.

513 Overall from our work, it was demonstrated that more quenching by resveratrol occurred when

514 binding $\beta$-lactoglobulin in the native than in nanoparticle form. Resveratrol bound native $\beta$ - $\mathrm{Lg}$

515 following the Stern-Volmer static quenching model at ratio 1: 1 in agreement with previously

516 reported by Liang et al. (2008); most probably resveratrol bound at the surface of the protein. On

517 the other hand, the heat denaturation undergone by the protein during the formation of the 
nanoparticles exposed new binding sites to which resveratrol bound. The quenching was not as

519 strong as with native $\beta$ - $\mathrm{Lg}$ but these type of interactions (most probably of hydrophobic nature)

520 led to further structural changes in the protein as shown by the shift to longer wavelengths. This

521 may also explain the protective effect of nanoparticles against chemical changes in resveratrol

522 upon heating and the increased antioxidant activity.

523 Denaturation of the protein affects the binding of different ligands in different ways. For 524 example, Liang and Subirade (2012) found that thermal denaturation of $\beta$-Lg reduced the binding 525 affinity for tocopherol whilst it increased for resveratrol. Moreover, Shpigelman et al. (2010) 526 reported a higher association of heated $\beta$-Lg with Epigallocatechin-3-gallate (EGCG) than native $527 \quad \beta$-Lg whilst Perez, Andermatten, Rubiolo, and Santiago (2014) demonstrated no significant 528 differences between native and heat-induced $\beta$-Lg aggregates binding to linoleic acid. Protein 529 denaturation leads to structural changes which then can change access to binding sites in the 530 protein; polarity and size of the ligands influences which binding sites their bind to.

\section{Conclusions}

533 In this work, the solubility of resveratrol in water was determined as $7 \mathrm{mg} / 100 \mathrm{ml}$ by the direct 534 spectrophotometric method and Folin-Ciocalteu method. Resveratrol was not stable to light, and 535 light exposure resulted in higher phenolic content and total antioxidant capacity. Nanoparticles of $536 \beta$-lactoglobulin were produced in the presence of resveratrol with average size around $181.8 \mathrm{~nm}$ 537 and the concentration of resveratrol had no significant difference in the size of nanoparticles. The 538 heat induced isomerisation of resveratrol at $75^{\circ} \mathrm{C}$ led to increased solubility but reduced 539 antioxidant capacity. $\beta$-lactoglobulin nanoparticles showed a protective effect against heat induced

540 loss of antioxidant activity. Moreover, when resveratrol with and without protein was treated at 
541 pasteurisation conditions both, native and $\beta$-lactoglobulin nanoparticles showed a protective effect

542 against heat induced loss of activity and an increase in antioxidant activity. Fluorescence

543 measurements of resveratrol binding to native $\beta$-Lg showed strong fluorescence quenching of $\beta$ -

544 Lg by resveratrol suggesting strong interactions between these two molecules. Interactions with $\beta$ -

545 Lg nanoparticles led to smaller quenching but a significant shift of $\lambda$ max to longer wavelengths

546 which suggested also strong interactions with resveratrol. Overall it was found that the interactions

547 of protein and resveratrol in combination with heating led to improved antioxidant capacity. Thus,

548 complexation of protein with resveratrol proved to have a stabilization effect. These findings are

549 very relevant for the optimum processing and formulation of resveratrol.

$550 \quad$ Acknowledgements

551 The trans-resveratrol powder was supplied by Evolva. Special thanks to MSc student Napatsawan

552 Wonggotwarin, who initiate this work. This research did not receive any specific grant from

553 funding agencies in the public, commercial, or not-for-profit sectors.

554 Conflict of interest statement

555 The author declares that there are no conflicts of interest.

556 References

557 Amri, A., Chaumeil, J. C., Sfar, S., \& Charrueau, C. (2012). Administration of resveratrol: What 558 formulation solutions to bioavailability limitations? Journal of Controlled Release, 158(2), $559 \quad 182-193$.

560 Benzie, I. F. F., \& Strain, a. J. (1996). The Ferric Reducing Ability of Plasma (FRAP) as a Measure 561 of "Antioxidant Power": The FRAP Assay. Analytical Biochemistry, 239(1), 70-76.

562 Bhat, K. P. L., \& Pezzuto, J. M. (2002). Cancer Chemopreventive Activity of Resveratrol. Annals 
of the New York Academy of Sciences, 957, 210-229.

564 Burdocka, G. A., \& Carabin, I. G. (2004). Generally recognized as safe (GRAS): history and description. Toxicology Letters, 150(1), 3-18.

566 Burns, J., Yokota, T., Ashihara, H., Lean, M. E. J., \& Crozier, A. (2002). Plant Foods and Herbal Sources of Resveratrol. Food Chemistry, 50(11), 3337-3340.

Catalgol, B., Batirel, S., Taga, Y., \& Ozer, N. K. (2012). Resveratrol: French paradox revisited. Front Pharmacol, 3(141), 1-18.

Duarte, A., Martinho, A., Luís, A., Figueiras, A., Oleastro, M., Domingues, F. C., \& Silva, F. (2015). Resveratrol encapsulation with methyl-b-cyclodextrin for antibacterial and antioxidant delivery applications. Food Science and Technology, 63(2015), 1254-1260.

573

574

575

576

EricDufour, Genot, C., \& Haertlé, T. (1994). $\beta$-lactoglobulin binding properties during its folding changes studied by fluorescence spectroscopy. Biochimica et Biophysica Acta (BBA) Protein Structure and Molecular Enzymology, 1205(1), 105-112.

Filipa, V., Plockováa, M., Šmidrkala, J., Špičkováa, Z., Melzochb, K., \& Schmidtc, Š. (2003). Resveratrol and its antioxidant and antimicrobial effectiveness. Food Chemistry, 83(4), 585-593.

Flieger, J., Tatarczak-Michalewska, M., \& Blicharska, E. (2017). Characterization of the cis/trans Isomerization of Resveratrol by High-Performance Liquid Chromatography. Analytical Letters, 50(2), 294-303

Fonseca, D. P., Khalil, N. M., \& Mainardes, R. M. (2017). Bovine serum albumin-based nanoparticles containing resveratrol: Characterization and antioxidant activity. Journal of Drug Delivery Science and Technology, 39, 147-155.

Gambini, J., Inglés, M., Olaso, G., Lopez-Grueso, R., Bonet-Costa, V., Gimeno-Mallench, L., .. . 
Borras, C. (2015). Properties of Resveratrol: In Vitro and In Vivo Studies about Metabolism, Bioavailability, and Biological Effects in Animal Models and Humans. Oxidative Medicine and Cellular Longevity, 2015, 1-14.

Gorji, E. G., Rocchi, E., Schleining, G., Bender-Bojalil, D., Furtmüller, P. G., Piazza, L., . . TocaHerrera, J. L. (2015). Characterization of resveratrol-milk protein interaction. Journal of Food Engineering, 167(2015), 217-225.

Guo, Y., Harris, P., Kaur, A., Pastrana, L., \& Jauregi, P. (2017). Characterisation of b-lactoglobulin nanoparticles and their binding to caffeine. Food Chemistry, 71(2017), 85-93.

594 He, Z., Zhu, H., Xu, M., Zeng, M., Qin, F., \& Chen, J. (2016). Complexation of bovine $\beta$ lactoglobulin with malvidin-3-O-glucoside and its effect on the stability of grape skin anthocyanin extracts. Food Chemistry, 209, 234-240.

Jang, M., Cai, L., Udeani, G. O., Slowing, K. V., Thomas, C. F., Beecher, C. W. W., . . Pezzuto, J. M. (1997). Cancer Chemopreventive Activity of Resveratrol, a Natural Product Derived from Grapes. Science, 275(5297), 218-220.

Jeon, Y. O., Lee, J.-S., \& Lee, H. G. (2016). Improving solubility, stability, and cellular uptake of resveratrol by nanoencapsulation with chitosan and -poly (glutamic acid). Colloids and Surfaces B: Biointerfaces, 147(2016), 224-233.

603 Jimenez-Garcia, S. N., Guevara-Gonzalez, R. G., Miranda-Lopez, R., Feregrino-Perez, A. A., 604 Torres-Pacheco, I., \& Vazquez-Cruz, M. A. (2012). Functional properties and quality 
in Enzymology, 299(1999), 152-178.

610 Lee, D.-U., Kim, H. M., Lee, D. G., Jeon, S.-H., Lee, J.-J., \& Lee, S. (2014). Effects of Thermal Treatments on the Stability of trans-Resveratrol and Yeast Inactivation in transResveratrol-Amplified Grape Juice. Archives of Biological Sciences, 66(1), 323-329.

Liang, L., \& Subirade, M. (2010). Beta-Lactoglobulin/Folic Acid Complexes: Formation, Characterization, and Biological Implication. The Journal of Physical Chemistry B, 114(19), 6707-6712.

Liang, L., \& Subirade, M. (2012). Study of the acid and thermal stability of b-lactoglobulin-ligand complexes using fluorescence quenching. Food Chemistry, 132(4), 2023-2029.

Liang, L., Tajmir-Riahi, H. A., \& Subirade, M. (2008). Interaction of $\beta$-Lactoglobulin with Resveratrol and its Biological Implications. Biomacromolecules, 9(1), 50-56.

Lipinski, C. (2002). Poor Aqueous Solubility_an Industry Wide Problem in Drug Discovery. American Pharmaceutical Review, 5(3), 82-85.

Lyons, M. M., Yu, C., R. B. Toma, Cho, S. Y., Reiboldt, W., Lee, J., \& Breemen, R. B. V. (2003). Resveratrol in Raw and Baked Blueberries and Bilberries. Journal of Agricultural and Food Chemistry, 51(20), 5867-5870.

Mikulski, D., Gorniak, R., \& Molski, M. (2010). A theoretical study of the structure-radical scavenging activity of trans-resveratrol analogues and cis-resveratrol in gas phase and water environment. European Journal of Medicinal Chemistry, 45(3), 1015-1027.

Orgován, G., Gonda, I., \& Noszál, B. (2017). Biorelevant physicochemical profiling of (E)- and (Z)-resveratrol determined from isomeric mixtures. Journal of Pharmaceutical and Biomedical Analysis 138, 322-329.

Penalva, R., Esparza, I., Larraneta, E., Gonzalez-Navarro, C. J., Gamazo, C., \& Irache, J. M. 
(2015). Zein-Based Nanoparticles Improve the Oral Bioavailability of Resveratrol and Its Anti-inflammatory Effects in a Mouse Model of Endotoxic Shock. Journal of Agricultural and Food Chemistry, 63(23), 5603-5611.

635 Perez, A. A., Andermatten, R. B., Rubiolo, A. C., \& Santiago, L. G. (2014). b-Lactoglobulin heatinduced aggregates as carriers of polyunsaturated fatty acids. Food Chemistry, 158(2014), 66-72.

Pujara, N., Jambhrunkar, S., Wong, K. Y., McGuckin, M., \& Popat, A. (2017). Enhanced colloidal stability, solubility and rapid dissolution of resveratrol by nanocomplexation with soy protein isolate. Journal of Colloid and Interface Science, 488(2017), 303-308.

Pund, S., Joshi, A., \& Patravale, V. (2016). Improving bioavailability of nutraceuticals by nanoemulsification. In A. M. Grumezescu (Ed.), Nutraceuticals Nanotechnology in the Agi-Food Industry (Vol. 4, pp. 481-534). London: Elsevier Inc.

Rabinow, B. E. (2004). Nanosuspensions in drug delivery. Nature Reviews Drug Discovery 3(9), 785-796.

Re, R., Pellegrini, N., Proteggente, A., Pannala, A., Yang, M., \& Rice-Evans, C. (1999). Antioxidant activity applying an improved ABTS radical cation decolorization assay. Free Radical Biology \& Medicine, 26(9-10), 1231-1237.

Savjani, K. T., Gajjar., A. K., \& Savjani, J. K. (2012). Drug Solubility: Importance and Enhancement Techniques. International Scholarly Research Notices: Pharmaceutics, 2012, 1-10.

Shah, P., \& Modi, H. A. (2015). Comparative Study of DPPH, ABTS and FRAP Assays for Determination of Antioxidant Activity. International Journal for Research in Applied Science \& Engineering Technology 3(636-641). 
655 Shpigelman, A., Israeli, G., \& Livney, Y. D. (2010). Thermally-induced protein-polyphenol coassemblies: Beta lactoglobulin-based nanocomplexes as protective nanovehicles for EGCG. Food Hydrocolloids, 24, 735-743.

658 Soleas, G. J., Diamandis, E. P., \& Goldberg, D. M. (1997). Resveratrol: A Molecule Whose Time Has Come? And Gone? . Clinical Biochemistry, 30(2), 91-113.

660 Stojadinovic, M., Radosavljevic, J., Ognjenovic, J., Vesic, J., Prodic, I., Stanic-Vucinic, D., \& 661 Velickovic, T. C. (2013). Binding affinity between dietary polyphenols and b-lactoglobulin negatively correlates with the protein susceptibility to digestion and total antioxidant

664 Tran, P., Tran, T., \& Lee, B. (2013). Enhanced solubility and modified release of poorly water665 soluble drugs via self-assembled gelatin-oleic acid nanoparticles. Pharmaceutical 666 nanotechnology, 455(1-2), 235-240.

667 Zhang, J., Liu, X., Subirade, M., Zhou, P., \& Liang, L. (2014). A study of multi-ligand beta668 lactoglobulin complex formation. Food Chemistry, 15, 256-261.

669

670

671

672 
676

677

678

679

680

681

682

683

684

685

686

687

688

689

690 